\title{
3. ENGLISH LANGUAGE BOOK CLUB AND TRANSFORMATIVE LEARNING
}

\author{
Developing Critical Consciousness in the English Language Classroom in \\ a UK Further Education (FE) College and in a South African Township
}

\section{INTRODUCTION}

Education does not make us educable. It is our awareness of being unfinished that makes us educable. (Freire, 2001, p. 58)

Do not conform to the patterns of this world, instead be transformed by the renewing of your mind. (Romans 12,2)

This chapter aims to discuss the results of a qualitative action research study which sets out to capture the extent to which a 'Book Club' strategy can lead to transformative learning. The research was in two phases and in two distinct contexts. The first, with English language learners at London's South Thames College and the second, Delft, a township in Cape Town, South Africa, to explore whether transformative learning and a greater sense of critical consciousness would also occur.

\section{BOOK CLUB STRATEGY}

'Book Club' is an extensive reading programme where the books read are selfselected graded readers. The rationale behind using graded readers was to facilitate comprehension and to enable the readers to immerse themselves in the story (Lantolf, 2000; Laberge \& Samuels, 1974), whilst also encouraging word recognition and subsequently reducing the affective filter (Krashen, 2003). Graded readers enable English language learners to engage fully with the text, which means interpreting the text through the lens of their self-narrative (Duncan, 2012). This is key if learners are to use their cultural imagination, which is the process of re-examining our cultural histories and adapting these as we engage in discussions with other cultural perspectives which may differ from our own (Florio-Ruane \& DeTar, 2001).

The learners were given two weeks to read their graded readers outside of class and told to be prepared to discuss these different books on book club day where they would share food and drinks in the school café as they discussed the themes in the book and the themes that would naturally arise throughout the discussion. Conversational learning and dialogue are attributed great value by hooks (2010) 
and to this end, the teacher takes a Socratic role to encourage deeper discussion by asking questions, whilst being careful not to tell learners what to think or lead them to a 'right' answer and providing vocabulary to bridge gaps in communication. Instead, learners are encouraged to challenge each other and themselves. The teacher is meant to take a passive role and enable learners to lead discussion, 'thus sharing conversational leadership by combining viewpoints rather than arguing for a single interpretation' (Florio-Ruane \& DeTar, 2001, p. 69.) and for the discourse to invite contribution of personal narratives. 'Instead, the conversations unfolded as hybrid literary events in which voices and styles of reading and responding mingled' (Florio-Ruane \& DeTar, 2001, p. 67).

\section{BACKGROUND}

'Book Club' was piloted 3 years ago at London's South Thames College with a group of adult international English language learners from a range of countries including: Thailand, Turkey, South Korea, Colombia and Cameroon, who were studying English with a view to getting a British degree and for some in order to teach English in their country.

'Book Club' came about initially as a strategy to encourage learners to read in English. Most had expressed the opinion that reading was purely instrumental and all expressed their negative experience of reading in English as demoralising, tedious and labour-intensive due to the enormous load of unknown vocabulary. The idea was to foster the love of reading and in so doing also change the learner's reading identity as a reader in English with a view to incorporating reading in English as a social practice (Duncan, 2012). It was hoped this would subsequently have a positive effect on their English language acquisition and experience of learning English.

During this time, I had also started a BA in Lifelong Learning at Canterbury Christchurch in southern England as a mature student. The course led me to conduct a small-scale pilot study of these learners to explore the impact that their involvement with Book Club was having and to determine whether further investigation was warranted for an action research study.

The hegemony of globalisation, neoliberal policies and English as an international language as vehicles to prosperity and forces for good, calls for educators to empower their learners by providing opportunities in the classroom which foster and develop critical consciousness. The speed of change and degree of uncertainty we live in today, along with changing markets coupled with unprecedented levels of unemployment forcing people to migrate for work, demand that we know who we are as individuals and that we possess a strong sense of self that is confident enough to choose a course of life that we can be content with (Illeris, 2014).

I contend that the role of the educator is to provide opportunities for learners which facilitate, require and encourage questioning, validating and justifying. Lange (2012, p. 205) posits that 'although we cannot direct meaningful change, we can 
disturb a system by introducing a meaning-rich idea, question, or practice that responds to a shared need' (Lange, 2012, p. 205). These changes, I argue, can occur within a formal or informal context. Orr (2004) disagrees with the emphasis on the mastery of content and acquiring qualifications. This mirrors what Freire (1972) refers to as the 'Banking Mode' of education, where learners are not more than passive receptacles. This passivity leads to what C. Wright Mills (1959) refers to as 'cheerful robots' in the 'Sociological Imagination'.

Being critically aware enables the learner to engage with the world with greater discernment (Freire, 1987) and leads to the premise underlying this chapter which seeks to explore the following research question: To what extent does 'Book Club' lead to transformative learning and the development of critical consciousness?

The author maintains that taking an approach to English language teaching which fosters transformative learning, helps to enable adult English language learners to think more democratically and more critically, which in turn fosters a greater sense of agency in the construction and re-construction of beliefs or frames of reference. It is argued that this skill is necessary to negotiate meaning and to navigate in the multi-cultural world they live in as Subjects rather than objects. For Freire (1993, p. 18) a Subject can be described as, someone who 'knows and acts whereas objects are acted upon'.

They perceive that through their consciousness, even when they are not makers of their social reality, they transcend the constituting reality and question it ... students assume a critical posture to the extent that they comprehend how and what constitutes the consciousness of the world. (Freire \& Macedo, 1987, p. 49)

The epistemological stance underpinning transformative learning is constructivist and as such, views meaning as being socially constructed (Cranton \& Taylor, 2012, p. 5). This is manifest in the conceptual assumptions upon which Book Club is based: the principle that language use is inextricably linked to what is learned by any individual and begins in the social interactions in which he or she engages (Vygotsky, 1997). This chapter claims that a 'Book Club' strategy can spark a rebuilding and reconstructing process, which is the result of being exposed to other realities and world views. These frames of reference undergo scrutiny, which leads to a dialogue with the self and with others. Tisdell and Tolliver (2009) assert that engaging and working with the cultural imagination can lead to transformative learning by stimulating critical discussion.

Comparably, Freire (1972) refers to "conscientization" or critical consciousness and the empowerment which comes from being able to 'unmask and decipher' the ideologies underpinning texts, institutions as well as social and cultural practices. He argues that we ' ... first read the world and then the text'. Emphasising the importance of being critically conscious so as to challenge and question, which both he and Mezirow believe is a condition of being human (Mezirow, 2009; Freire, 1972). 


\section{RATIONALE FOR RESEARCH}

This research project is informed by the findings of an earlier small-scale study which was designed mainly to alter beliefs and preconceptions regarding reading in English as a second language and to foster a love for reading. Upon further observation of these same learners and my reflection-in-action (Schön, 1983), I noticed a change in their behaviour. They seemed much more critical and open to dialogue at a much deeper level, whilst also displaying a marked willingness and openness to other points of view and a desire to explore possibilities in class discussion that they had not considered in the past. In addition, and of great importance, was a sense of empowerment that was observable in the way they spoke and in the way that they carried themselves. It was this 'awakening' that spurred me to conduct a fresh literature review.

Furthermore, I contend that the reason I was able to recognise this 'awakening' in my learners is due to the fact that I myself was also undergoing transformative learning. Mezirow (2009, p. 22) defines this learning as a 'learning that transforms problematic frames of reference to make them more inclusive, discriminating, reflective, open and emotionally able to change'. Among the ten stages outlined, the first is what is referred to as a 'disorientating dilemma' (Mezirow, 2009, p. 19). Early on in the BA in Lifelong Learning, as a mature learner returning to higher education, I was experiencing an internal struggle which was highly emotive, as I faced the fear of failure and not measuring up coupled with a different learning culture. Despite a strong desire to learn and open my mind, there was also enormous anger and frustration as I was faced with ideas and concepts which not only challenged my established ways of thinking, but also compelled me to reflect critically coupled with a profound need to voice these reflections.

Although I did not understand what was happening, I was acutely aware that I was in the process of extreme change. There was no doubt that it was profound and that I was changing the way I viewed the world and this directly affected my role as a teacher, which in turn affected my perception of my learners.

The findings of the focus group, which had been taped but were informal, revealed surprising evidence which would suggest that the participants involved in Book Club had experienced transformative learning in terms of re-framing their negative frame of reference regarding reading in English (Mezirow, 2009). Furthermore, participants expressed increased levels of confidence, which had led to most feeling confident enough to read newspapers independently.

\section{LITERATURE REVIEW}

The fresh literature review included Mezirow and Associates' (2000) 'Learning as Transformation', Mezirow, Edward W. Taylor \& Associates' Transformative Learning in Practice: Insights from Community, Workplace, and Higher Education (2009), Freire $(1993,1972)$ 'Pedagogy of the Oppressed' and C. Wright Mills (2000) 
'The Sociological Imagination'. These have introduced me to critical theory, transformative learning theory, 'conscientization' and the 'Banking Model' of Education and the creation of the 'sociological imagination'. Overall, this is the bedrock for this research project.

\section{METHODOLOGY}

The methodology is qualitative Action Research (AR) within a transformative learning framework. AR is designed to improve professional practice, and is an approach which aims to improve education by changing it and learning from those changes, which resonates with transformative learning. My understanding of action research is encapsulated by Carr and Kemmis (1985) who describe action research as:

Simply a form of self-reflective enquiry undertaken by participants (teachers, students or principals for example) in social (including educational) situations in order to improve the rationality and justice of (a) their own social or educational practices, (b) their understanding of these practices, and (c) the situations (and institutions) in which these practices are carried out. (Carr \& Kemmis, 1985, p. 162)

It is a cyclical process which leads to critical reflection. The democratic participation emphasised in AR respects the contributions of the participants and recognises the practitioner as 'expert' and a significant contributor in his/her professional development' (McNiff, 1988).

Qualitative methods were used to collect data, which was in two phases. In phase one individual semi-structured interviews were used to obtain a more-detailed description of their experiences. Participants were given a copy of the questions to refer to, so as to support listening comprehension. These participants are also English language learners from London's South Thames College. 'Jane', a 42-year old woman from South Korea is married and has taken a year's sabbatical from work in the Cyber Crime division to come to London with her husband. She clearly identifies Confucianism as the foundation of her beliefs, values and frames of reference. 'Patricia' is a 24-year-old woman from Cameroon, who aims to gain a British degree. She has expressed that her culture places great value on marriage and qualifications. Both have received a banking model of education (Freire, 1996), especially in Jane's case, which she highlights as extremely negative. 'We just memorise ... never discuss'.

Significantly, both candidates were profoundly impacted by this process, with Patricia experiencing a moment of epiphany as she realised at the end of the interview that she loved reading (Mezirow, 2009). Jane felt compelled to critically reflect and expressed this at the second interview, explaining that she went on to research Confucianism to get a clearer understanding of her long-held beliefs to understand her own behaviour and perceptions. She seemed disoriented by the fact that she had never questioned them before. 
Selection of participants was based on the researcher's observation of them in class and observable perceived changes. However, both participants are generally guarded and have had negative experiences of authority figures. There was a meeting before the interview to explain the process thoroughly and to allow for any questions. They were reminded that they could leave the process at any time and were under no obligation to participate. Both seemed excited, but also apprehensive. Furthermore, participants were given a copy of the transcript (verbatim) before the second interview for member checking (Kvale, 2010). Interestingly, both checked for grammatical mistakes.

With a view to making the process democratic and to maintaining authenticity and fidelity (Kvale, 2010) interviewees were given the option to bring visual aids, such as photographs, art and examples of narratives which expressed their feelings. The researcher was aware of Jane's keen interest in art and felt it would help Jane to express how she experiences and makes sense of the world. Interestingly, Jane chose Bacon's Three Sides of Freud and brought the print with her and used it to explain her experience of speaking in English.

Another strategy was to use concept questions, or questions to check understanding and paraphrasing to deal with unknown vocabulary (British Council, 2006). For instance, 'Is powerful the right word? Is that what you want to say?' Interestingly, Jane chose Bacon's Three Sides of Freud to help her express herself.

Interviews were recorded and subsequently transcribed to aid the analytical process and highlight salient themes. This was time-consuming but thematic analysis was found to be appropriate. Participants were given copies before the second interview for member checking (Kvale, 2010).

Phase 2 involved a change in context in terms of learning culture and background of participants. These learners are from Delft, a township in Cape Town, South Africa, who were attending an English Club I was running as a volunteer, at Bettaway Community Church. This was my second visit to Delft. Delft is a township in Cape Town and has one of the highest crime rates and substandard education. The method chosen was a focus group, conducted via Skype consisting of two females. The reasons for this were distance, and to obtain as much data as possible via their interaction with each other. This was later transcribed verbatim and used in the text.

Rochelle is what is referred to as 'coloured' and her first language is Africaans. She is married and has two sons. Zodwa is referred to as 'black', and her first language is Xhosa. She is a single mother of two sons. She lives with no clean running water or indoor toilet and lives in one of the most dangerous areas in Delft. Both have an elementary level education. By means of triangulation data collection methods and findings were compared, as were context and background.

\section{DISCUSSION OF FINDINGS}

The results of the semi-structured interviews revealed three salient themes where there is persuasive evidence which demonstrates that the participants exhibit signs 
of having undergone 'perspective transformation' (Mezirow, 2009) in the areas of: attitudes to learning English, the freedom to be fully who you are and heightened cultural awareness. Furthermore, there are examples of what Freire (1972) refers to as 'conscientization' or critical consciousness, and how Book Club, through the books that are read and what Iser (1972) refers to as the 'work', fosters conditions for critical reflection. He explains that first, there is the 'text', and that it is through the interplay between the reader and the reader's interpretation of the 'text', informed by the reader's self-narrative, that meaning is given. There is a constant reconstructing and constructing of meaning, which mirrors transformative learning.

Zodwa seems to be engaging with her cultural imagination (Florio-Ruane \& De Tar, 2001) and bringing her personal narrative as she interprets the book which mirrors what life is like for her and Rochelle. She is re-examining her frames of reference and identifying other ways of being.

Zodwa: $\quad$ Look, like when I read the book 'Street Life' it tells about our life, no? And you think "How did the writer think of this book, these characters? If you are reading this book and you find that a person is in a certain situation and what is the solution, we can really think It's not so bad. Sometimes when you read a book maybe you upset, and you find yourself thinking Wow!

Researcher: So it changes your way of thinking?

Zodwa: Yeah, it's a good thing!

This process triggered critical reflection as she engaged with topics and issues not only from her reading, but also through dialogue, which in some cases compelled the participants to reassess and reconstruct their 'frames of reference' with a greater sense of agency and critical consciousness. hooks (2010, p. 46) reminds us that conversational learning is powerful and exposes us to 'different ways of seeing and knowing'. Significantly, she emphasises that the act of conversation can create a safe space which generates compassion. According to hooks (2010, p. 46) compassion is essential as it stimulates a desire to communicate and understand.

These are learners who are no longer happy to blindly or passively accept ways of thinking without challenge. There has been an 'awakening' in their consciousness. Taylor and Jarecke (2009, p. 277) refer to a kind of learning which is profound and goes beyond instrumental learning, which seeks only to improve performance (Taylor, 2009 , p. 20), whereas communicative learning is concerned with understanding what people mean when they communicate (Taylor, 2009, p. 20). Long-held beliefs and values are called into question through dialogue, requiring critical reflection. This is learning where learners 'experience personal social empowerment' (Taylor \& Jarecke, 2009, p. 277).

Significantly, the participants from the townships in Delft have become more autonomous and are taking ownership of their learning by making it their own. The agency demonstrated suggests an increase in confidence to take initiative and in their 
own ability. It is important to remember that these women have not been educated past elementary school and have never demonstrated this level of autonomy before. In addition, it is interesting to note their interest in individual words. When I was there teaching and setting up Book Club in August 2015, they learnt the word 'enthusiastic', and 'unwind' was learnt in August 2011, during my first visit there. Both Rochelle and Zodwa make a point of showing me they know these words and can use them in the correct context.

Rochelle: Yes! We decided that if there are words that we don't understand that we make copies for each one. At the back of the book is the words and the meanings of the words. So, everyone get a copy and we go over it. We try to pronounce it and so on.

Zodwa: Yes, we very enthusiastic!

Rochelle: We don't want just to read it. We want to understand so we make copies for each one to go over it at home and so on.

Researcher: What happens in your mind when you're reading?

Rochelle: Like you unwind.

One major theme of transformational learning was language learning, which further corroborates the experience voiced by participants in the earlier pilot study. In a study conducted by King (1999) into which found that language learning is conducive to fostering transformative learning in English language learners. For example, Patricia described her experience of reading as purely instrumental.

We just read to pass an exam ... reading is just losing your time ... reading is just for when you have to ... Before, I was angry when I was reading and I don't understand. I would just give up ... How am I going to do it ... I was afraid to read and to explain in English ... Now I sometimes find newspapers and I just pick it.

This is significant because it demonstrates a desire in Patricia to engage with reading as a social practice (Duncan, 2012). This is a dramatic paradigm shift for Patricia, which supports Duncan's view $(2012$, p. 2) that there is persuasive evidence which strongly supports the notion that reading circles develop not only reading and discussion skills, but also 'independent study skills, confidence as both readers and members of the community, the exploration of personal identity and the development of personal reading practices'.

Jane from South Korea and Patricia from Cameroon expressed an increased desire to read more and increased confidence levels due to Book Club. Significantly, the same was true for Rochelle and Zodwa, from Delft, despite the vast differences in their backgrounds in terms of education, cultural background and standard of living. Both contexts seem to be examples of what Duncan (2010) describes as a shift in 'reading identity' and illustrates an example of 'internal' change due to participation in Book Club. This change in perspective was incremental, occurring over a period 
of time, and as a result of feeling a sense of achievement at being able to finish an entire book and discuss it fluently and confidently.

In addition, Rochelle also seems to be reflecting critically and there is persuasive evidence to suggest that Book Club is enabling them to pass on the love and habit of reading to their children. Bourdieu (1986) refers to these dispositions as habitus.

Rochelle: I am reading more now. In the evening Keon asks "Are we not gonna read Mommy?" He want to read in the evening and now I must read again. So, it's more now. It's our duty to read for them. We must also read the books. We do it and then they do it also.

This is significant because it will enable not only Rochelle but her children to move within a wider range of 'fields' as they gain social and linguistic capital (Bourdieu, 1986).

Rochelle: That book that I read about scientists. There is stuff that I didn't know so through that book I did learn about stuff that I didn't know. It's good because there's a lot of stuff that you don't know. Then you read and I think then your thinking and your mind set I think it changes. Like let's say your child might have a project about scientists, you can help him.

Both Rochelle and Zodwa feel more empowered to help their children and themselves despite the apparently insurmountable challenges they face on a daily basis. A second major theme of transformational learning is the freedom to be fully who you are.

When I choose new book it was interesting because for example South Africa president ... I choose Mandela's book. He was famous in the world and I choose when he was not died. So ... he is black president ... so I heard his story but when I read the book I understand his life and why people choose ... after I read book when I listened to the news about South Africa I interested in that news. It's connected.

Jane was intentional and discriminating in her book selection. Furthermore, her choice of book reveals a desire to explore and broaden her cultural awareness so as to open her mind (Cranton \& Taylor, 2013, p. 37) to other ways of thinking and other ways of knowing, which are far-removed from her own (Belenky et al., 1997). It also demonstrates a willingness to change, which is one of the democratic ideals in communicative learning as stipulated by Mezirow (2009) and is also an example of what Florio-Roune and DeTar (2001) describe as 'cultural imagination. There is reasonable evidence to suggest that Jane is experiencing the beginnings of conscientization or critical consciousness as she demonstrates signs of 'reading the world' (Freire \& Macedo, 1987). 
So ... when I came here I saw another country classmates and they are very free!! I was surprised and I wanted to be like them!

Comparably, the feeling of disorientation in Mezirow's (2009) stages of transformative learning can also be seen in stage 2 of culture shock as experienced when there is a meeting between different cultures (McClinton, 2005). When faced with her Colombian and Italian classmates Jane was stunned by their expressiveness and perceived lack of inhibitions, causing her to experience culture shock, which acted as a catalyst for her to challenge her established way of thinking and behaviour. Jane explains that because of her Confucian principles she had always obeyed teachers and parents. And now realises she had been conditioned to conform and follow convention unquestioningly. There is also convincing evidence to suggest that this is also an example of what Freire (1993) means by "conscientization" and Habermas (no date, cited in Mezirow, 1981, p. 7) regards as emancipatory action, which is when taken-for-granted social roles and expectations and habitual ways of behaving are challenged by the process, Freire (1972) calls these 'problem-posing'.

My background culture is Confucianism. I checked this. Children respect parent and teachers. So when I was growing up I didn't have questions for anything because children respect adults because Confucianism, so I ALWAYS obeyed people in authority. So when I had Book Club it's very useful for me to read the book and then explain to another classmate ... I have chance to explain my book and I give my opinion to another classmate. I share my opinion. It's very good.

Jane comes from a Banking Model of education, which is designed to destroy any desire to question and renders individuals passive and unable to think critically. Added to this, her society is underpinned by the Confucian saying 'Silence is Gold' and expressing one's opinion is frowned upon. This is maintained through the threat of alienation. Despite these seemingly insurmountable obstacles, Jane is engaging in what Brookfield (1995) describes as ideology critique.

Jane selected Bacon's painting Three sides of Freud, as a metaphor to represent how not being able to speak fluently in English constrains her and also to represent the freedom she longs for. Initially, she feels trapped, but there is now more space, which she explains represents an increase in self-confidence. The affective factor, which Mezirow has been criticised for not addressing in depth, would seem to be a significant factor in her transformative learning. Her feelings and emotions are powerful and have played a major role, compelling her to critically reflect and challenge the values and beliefs that had been assimilated unquestioningly (Mezirow, 2009).

Jane: $\quad$ My speaking is not good. So when I speaking during the Book Club I'm like him, sitting on the chair and I want to go out of the swing.

Researcher: So ... does that mean that in this painting he's trapped?

Jane: $\quad$ Yes, so this colour (the golden yellow) ... it's very beautiful ... so if I stand outside, I can enjoy this space. 
Researcher: And that space represents?

Jane: $\quad$ Free!

Vygotsky (2012) explains that the 'flow of thought is not accompanied by a simultaneous unfolding of speech' and he stresses that the cognitive process has its own framework and reminds us that the transition from thought to the speech act is not an easy one. He adds, 'Every sentence that we say ... has some kind of subtext, a thought behind it' (Vygotsky, 2012, pp. 264-265). Jane is illustrating the internal struggle, which can be involved in perspective transformation, and which Meizirow (2009, p. 19) describes as Phase 2, where there is a 'recognition of a connection between one's discontent and the process of transformation'.

It could also be argued that Jane is struggling with not being able to be her 'true' self in English. She seems to be struggling with 'losing her genuineness' (Foster, p. 35) due to the restrictions imposed by her limited range of competence in English, which she does not experience in Korean. This sense of loss can contribute to transformative learning as the language learner's self-perception is made vulnerable or re-examined, and is often a painful and disturbing process (Mezirow, 1991; McClinton, 2005).

Belenky et al. (1997) posit that there is a correlation between women whose sense of self is embedded in external definitions, institutions and roles and women who gain fulfilment from pleasing others or measuring up to external standards such as 'the good woman', 'the good student' or the 'successful woman'. Jane explains that one of the reasons why she feels torn about embracing the freedom she claims to desire or aspire to, is that she enjoys the approval, validation and praise she receives when she complies with the stereotypical roles and principles of Confucianism.

Because my parents say 'You are very good child ... my friends say You are very good person ... my colleagues Oh! You are the best partner! I want to be that kind of person. I always give something to everyone so that they will tell me Oh! You are a very kind person!

This seems to be an example of what Mills (2000) refers to as the problem of 'the cheerful robot' and asserts that apparent desire for freedom is not inherent in Man. Jane refers to the fear that came with that desire for freedom. Her fears of alienation and losing the comfort and security of the life and reality she has known.

Rochelle now realises that others saw her as one-dimensional, funny and someone who didn't take anything seriously. She is no longer content to be seen this way and now enjoys the fact that she is more highly-regarded. She has found her voice and enjoys using it.

Zodwa: I was feeling excited because I was sharing that story with them and they were like asking even more questions 'What happened ...?'

Researcher: How did you feel doing that?

Zodwa: I feel great man! 
Rochelle: They are LISTENING to you!

Researcher: And that's important?

Rochelle: Some people say "You don't even take notice of this and that and now you talking about this book that you have read and explaining everything.

Researcher: So it's changing the way other people see you?

Rochelle: Yes, it's a good thing. You know, people think Rochelle is JUST funny. But there's a serious part of me also. If they see that side they think 'What's up with Rochelle?' Maybe they ask me Sister Rochelle, are you OK? You're so quiet. But I think to myself, No I'm not quiet, I'm just THINKING. They say "I never saw you like that before".

Researcher: How did that make you feel?

Rochelle: It's nice to let people see another side of me. Not only that side that they know. It's not always jokes, jokes! It's just that stuff changes. Sometimes they catch me in the middle of thinking mood and they think something's wrong, but nothing's wrong.

Conversational learning is powerful in transformative learning because it not only provides the place to be heard, but also its democratic nature assumes every voice is worthy, generating compassion and a 'book club' discourse where participants combine 'book talk' with 'self-talk' (Florio-Ruane \& de Tar, 2001).

The third theme highlighted was heightened cultural awareness and critical consciousness.

Jane: $\quad$ So ... another for example ... I read Barack Obama book ... yeah ... before I liked Barack Obama ... who is president ... yeah ... he's a good person ... I just know information about him ... and I read Barack Obama story book ... yeah ... Why in America big issue Barack Obama's religion? ... and then ... Why Barack Obama wanted to change the politics in the USA? ... and in the world ... in Afghanistan ... Why USA fight Afghanistan? Before I don't ... didn't interested in that kind of book. It's not my life.

Researcher: So you weren't interested ... it was completely ... J

Jane: Different.

Researcher: From you ... separate from you?

Jane: $\quad$ Yeah, I didn't even think about it.

There is evidence to show that she is beginning to 'read the world and then the text' (Freire \& Macedo, 1987, p. 49) by unmasking and deciphering the ideologies, underpinning texts, institutions, social and cultural practices. She is showing signs of critical consciousness and engagement with the world as a Subject and no longer an object. 
Both Patricia, from Cameroon and Zodwa, from Delft highlight the importance of being more tolerant and not judging. When asked how 'Book Club' had changed her life Zodwa replied:

Zodwa: $\quad$ Now as we come together to explain our books, I will explain it my way and she will explain it her way. It came into to my mind that you expect another explanation and you don't have to judge that explanation of that person.

Patricia: Now I am more tolerant. The first Book Club when she said she didn't like children I was very angry and I wanted to punish her. Now, I don't need to judge. I am more tolerant.

\section{CONCLUSION}

Fostering an environment which leads to transformative learning, where individuals cultivate a greater sense of agency and are empowered to make sense of the world through consciousness-raising, is in my view significant and crucial in adult learning.

As English language learners, these learners not only have the formidable task of learning the language, but also the culture, whilst being immersed in the second language culture. This research has highlighted areas such as acculturation and the importance of identity and being authentic in a second language, which had not previously been considered as elements which could foster transformative learning.

There is strong support for incorporating strategies such as Book Club, where these learners can have a voice. This was evident in all the participants. Furthermore, there is persuasive evidence to suggest that a 'Book Club' strategy does seem to foster transformative learning. I believe that the 'book club' discourse, which is a mixing of 'book talk' with 'life talk', not normally welcome in the classroom, promotes engagement with their cultural imagination, triggering critical reflection and a reshaping of these cultural histories as they encounter different cultural perspectives (Florio-Ruane \& DeTar, 2001).

Practically, Action Research has had a profound impact on my practice, not only instrumentally, but in terms of my identity as an English language teacher. It has served as a catalyst to a re-examining of my own frames of reference, as I have become convinced that this role comes laden with my ideologies, my beliefs and my self-narrative, and as such there is the responsibility not to preach or to manipulate learners into taking on what teachers regard as true, fair or the right way of thinking or living. Freire (1993) reminds us to be careful not to become the new oppressor, however well-meaning.

To conclude, there was evidence which strongly supports the ideas of Freire (1972) and C. Wright Mills (2000), who highlight the detrimental effects of a Banking Model of education, which is characteristically 'necrophilic' as the relentless process of narration eradicates critical consciousness and the desire to question, producing "cheerful robots", who cannot make the effort to question the existing power system. 
Not only have these learners incorporated reading as a social practice and improved language acquisition, there is evidence of consciousness-raising and greater agency and ownership of their re-constructed frames of reference.

Therefore, the findings support an adult curriculum which incorporates strategies in English language teaching and learning, that are designed intentionally to help foster transformative learning.

\section{REFERENCES}

Belenky, M. F., Clinchy, M. B., Goldberger, R. N., \& Tarule, M. J. (1997). Women's ways of knowing: The development of self, voice, and mind. New York, NY: Basic Books.

Bourdieu, P. (1986). The forms of capital [Online]. Retrieved from August 12, 2015, from https://www.marxists.org/reference/subject/philosophy/works/fr/bourdieu-forms-capital.htm

Brookfield, S. (1995). The power of critical theory for adult learning and teaching. Maidenhead: Open University Press.

Cranton, P., \& Taylor, E. (2012). The handbook of transformative learning: Theory, research, and practice. San Francisco, CA: Jossey-Bass.

Duncan, S. (2012). Reading circles, novels and adult reading development. London: Continuum.

Florio-Ruane, S., \& DeTar, J. (2001). Teacher education and the cultural imagination: Autobiography, conversation and narrative. Mahwah, NJ: Lawrence Erlbaum Associates.

Foster, E. (1997). 'Transformative learning in adult second language learning' new directions for adult and continuing education, no. 74, Summer, Jossey-Bass Publishers [Online]. Retrieved from $\mathrm{http} / / /$ onlinelibrary.wiley.com/doi/10.1002/ace.7404/epdf?r3_referer=wol\&tracking_action=preview_ click\&show_checkout $=1 \&$ purchase_referrer $=$ onlinelibrary. wiley.com\&purchase_site_license $=$ LICENSE DENIED

Freire, P. (1972). The pedagogy of the oppressed. London: Penguin Group.

Freire, P. (1993). The pedagogy of the oppressed. London: Penguin Group.

Freire, P. (2001). Pedagogy of freedom: Ethics, democracy, and civic courage. Lanham, MD: Rowman and Littlefield, Publishers.

Freire, P., \& Macedo, D. (1987). Literacy: Reading the word and the world. London: Routledge and Kegan Paul Ltd.

hooks, b. (2010). Teaching critical thinking: Practical wisdom. New York, NY: Routledge.

Ileris, K. (2014). Transformative learning and identity. Oxon: Routledge, Taylor and Francis Group.

Iser, W. (1972). The reading process: 'A phenomenological approach': A new literary history, on interpretation (Vol. 3, no. 2, pp. 279-299). Baltimore, MD: The Johns Hopkins University Press. Retrieved April 12, 2015, from http://www.jstor.org/stable/468316

King, K. P. (1999). Changing languages, cultures and self: The adult ESL experience of perspective transformation. Retrieved from http://www.adulterc.org/applications/ClassifiedListingsManager/ inc_classifiedlistingsmanager.asp?ItemID $=458 \&$ CategoryID $=134$

Krashen, S. (1988). Steven Krashen's theory of second language acquisition [Online]. Retrieved April 14, 2014, from http://www.sk.com.br/sk-krash.html

LaBerge, D., \& Samuels, S. J. (1974). Toward a theory of automatic information processing in reading. Cognitive Psychology, 6, 293-323.

Lange, E. A. (2012). Transforming transformative learning through sustainability and the new science. In E. W. Taylor, P. Cranton, \& Associates (Eds.), The handbook of transformative learning: Theory, research, and practice (Chapter 12). San Francisco, CA: Jossey-Bass.

Lantolf, J. P. (2000). Sociocultural theory and second language learning. Oxford: Oxford University Press.

Mertens, D. (2009). Transformative research and evaluation. London: The Guilford Press.

Mezirow, J. (1991). Transformative dimensions of higher and adult education [Online]. San Francisco, CA: Jossey-Bass. Retrieved from https://www.amazon.co.uk/Transformative-Dimensions-JosseyBass-Education-Hardcover/dp/1555423396 
Mezirow, J., \& Associates. (2000). Learning as transformation. San Francisco, CA: Jossey-Bass.

Mezirow, J., \& Taylor, E. W. (2009). Transformative learning theory. In J. Mezirow, E. W. Taylor, \& Associates (Eds.), Transformative learning in practice: Insights from community, workplace, and higher education. San Francisco, CA: Jossey-Bass.

McClinton, J. (2005). Transformative learning: The English as a second language teacher's experience. The CATESOL Journal, 17, 1. Retrieved from http://www.catesoljournal.org/wp-content/uploads/ 2014/07/CJ17_mcclinton.pdf

McNiff, J. (1988). Action research principles and practice. London: MacMillan Education Ltd.

Mills, C. W. (2000). The sociological imagination. Oxford: Oxford University Press.

Orr, D. (2004). Earth in mind. Washington, DC: Island Press.

Power, J. (2012). Does Confucianism have a role in Korea today? [Online]. Retrieved July 3, 2014, from http://www.koreaherald.com/view.php?ud=20120213001231

Raphael, T. E., Florio-Ruane, S., \& George, M. (2001). Book club plus: A conceptual framework to organize literacy instruction. Language Arts, 79(1), 159-168. Retrieved July 5, 2014, from https:/www.learner.org/libraries/engagingliterature/support/book-club-plus.pdf

Romans 12, v2, New International Version of the Bible.

Schon, D. (1983). The reflective practitioner: How professionals think in action. New York, NY: Basic Books.

Taylor, E. W. (2009). Fostering transformative learning. In J. Mezirow, E. W. Taylor, \& Associates (Eds.), Transformative learning in practice: Insights from community, workplace, and higher education. San Francisco, CA: Jossey-Bass.

Taylor, E. W., \& Cranton, P. (2013). A theory in progress? Issues in transformative learning theory. European Journal for Research on the Education and Learning of Adults, 4(1), 33-47. Retrieved July 19, 2014, from http://www.pedocs.de/volltexte/2013/7705/pdf/RELA_2013_1_Taylor_Cranton_A_ theory_in_progress.pdf

Taylor, E. W., \& Jarecke, J. (2009). Transformative learning theory. In J. Mezirow, E. W. Taylor, \& Associates (Eds.), Transformative learning in practice: Insights from community, workplace, and higher education. San Francisco, CA: Jossey-Bass.

Vygotsky, L. (1997). Mind and society Interaction between learning (pp. 77-91) [Online]. Retrieved form http://www.psy.cmu.edu/ siegler/vygotsky78.pdf

Vygotsky, L. (2012). thought and Language. Cambridge, MA: MIT Press.

\section{Ida Leal}

South Thames College

England 